\title{
Examining Training Motivations Among Public Health Workers
}

\author{
Nate C. Apathy, BS; Valerie A. Yeager, DrPH, MPhil
}

\begin{abstract}
Context: As public health needs and priorities evolve, maintaining a trained public health workforce is critical to the success of public health efforts. Researchers have examined training needs in various contexts and subpopulations, but a nationally representative study of what motivates public health workers to seek out training has yet to be conducted. By understanding these motivations, public health agencies and policy makers can appeal to worker motivations in both training programs and organizational incentives.

Objective: The purpose of this article was to describe overall training motivations and identify patterns of training motivations among public health workers. This study also explored whether or not training needs differ across prevalent motivational patterns.

Design and Participants: Using data from the 2017 Public Health Workforce Interests and Needs Survey (PH WINS), the study used latent class analysis (LCA) to identify motivational patterns and logistic regression to analyze associations with training needs.

Results: The most prominent motivation to seek training was personal growth $(82.7 \%$ of respondents). LCA identified 4 motivational classes of public health workers: those motivated by organizational pressure and requirements (31.8\%), those motivated indiscriminately by all factors (28.4\%), those motivated primarily by personal growth (21.7\%), and those motivated by organizational accommodations and supports (18.2\%). Motivational class was not associated with indicating training needs in any of 8 training domains, nor was it associated with indicating any training need in any domain.

Conclusions: Public health agencies should consider the different motivational classes present in the public health workforce. In particular, motivational classes that represent organizational choices suggest that public health agencies should both motivate workers with organizational requirements and pressure from managers and offer institutional support via paid travel and covered time for training.
\end{abstract}

KEY WORDS: latent class analysis, PH WINS, public health workforce, training motivation, training needs, workforce development

$\mathrm{n}$ the 20th century, public health programs and interventions have been estimated to have added 25 years to Americans' life expectancies. ${ }^{1}$ This represents more than $80 \%$ of the total life expectancy gains during that time, made possible by public health programs to increase vaccination

\footnotetext{
Author Affiliation: Health Policy \& Management, Richard M. Fairbanks School of Public Health, Indiana University, Indianapolis, Indiana.

The authors declare no conflicts of interest.

Supplemental digital content is available for this article. Direct URL citations appear in the printed text and are provided in the HTML and PDF versions of this article on the journal's Web site (http://www.JPHMP.com).

This is an open-access article distributed under the terms of the Creative Commons Attribution-Non Commercial-No Derivatives License 4.0 (CCBY-NC-ND), where it is permissible to download and share the work provided it is properly cited. The work cannot be changed in any way or used commercially without permission from the journal.
}

Correspondence: Nate C. Apathy, BS, Health Policy \& Management, Richard M. Fairbanks School of Public Health, Indiana University, 1050 Wishard Blvd, Floors 5 and 6, Indianapolis, IN 46202 (natea@iu.edu).

Copyright (c) 2019 The Authors. Published by Wolters Kluwer Health, Inc. DOI: $10.1097 / \mathrm{PHH} .0000000000000940$ rates, improve workplace safety, and decrease the incidence and prevalence of infectious disease, among others. ${ }^{2}$ The success of these programs depended upon a workforce equipped with the skills necessary to effectively deliver interventions. However, those skills and the requisite workforce training programs shift as population risks change, interventions evolve, and funding sources change. Indeed, even as public health programs have successfully mitigated factors reducing life expectancy, other risks have risen to the fore. ${ }^{3}$ During the last 25 years, chronic obstructive pulmonary disorder has become the third largest contributor to disability-adjusted life-years, behind heart disease and lung cancer. ${ }^{3}$ In addition, the rise of both obesity ${ }^{3,4}$ and opioid use disorder ${ }^{3,5}$ presents relatively new challenges to which public health agencies and programs must respond. ${ }^{6,7}$ This shifting landscape of risk and the accompanying shifts in funding structures and sources require nimble responses from the public health workforce, especially in equipping workers with the information and skills 
necessary to deliver effective interventions within constrained budgets. ${ }^{8}$ As risks change, different skill sets are required from the public health workforce to effectively mitigate health issues and related social determinants of health. As a result, one part of ensuring the effectiveness of public health programs involves understanding how best to approach training of the public health workforce, which includes both knowledge of workers' motivations for seeking training and knowledge of workers' training needs.

To inform efforts to mitigate training gaps among public health workers, researchers have thus far focused on examining the training needs of the public health workforce. ${ }^{9-17}$ These studies have found that policy-related domains, program budgeting, and use of evidence in decision making are common training needs $s^{9,11,13}$ and that executives and workers disagree on the importance of some training domains. ${ }^{16}$ Others have examined needs among subpopulations of public health workers. ${ }^{10-12,14,15,17}$ Understanding areas in which public health workers lack training is important for addressing these needs. However, examining training needs without the context of what motivates public health workers to seek out training leaves out important information pertinent to training program design and organizational incentives. Worker motivations can be emphasized in the marketing of trainings and organizational incentives to increase enrollment and more quickly address training needs. In addition, certain motivations to seek training may be more prevalent among workers exhibiting specific training needs; as such, strategies to address those needs may be more likely to succeed if they appeal to those more common motivations. Despite the prevalence of training needs studies, no nationally representative studies examining worker motivations to seek training have been conducted. One study examined the use of evidence-based decision making (EBDM) in public health. ${ }^{13}$ This included motivations to increase the use of EBDM; however, it did not investigate motivations to address broader training needs. Another study reported on a 2012 survey among public health workers in Nebraska examining training program preferences, some of which overlap with Public Health Workforce Interests and Needs Survey (PH WINS) motivations. ${ }^{12}$ This study found that in-person training is preferred to online training and that workers respond to leadership encouragement regarding trainings and also found that workers cited "lack of motivation" as a barrier to seeking out training. ${ }^{12}$ In summary, training motivations have not been deeply studied in the public health workforce training literature despite considerable research assessing training needs. In particular, a current, nationally representative study of public health worker motivations to seek training is needed.
The purpose of this study was first to describe overall training motivations and identify patterns of training motivations among public health workers. The study explored the characteristics of the public health workers who comprise each motivational group. Second, this study adds knowledge by exploring whether or not training needs differ by motivational group. The current study provides a nationally representative examination of overall training motivations and how motivations differ by worker characteristics and training needs. Given motivation's role in driving behavior, this study's findings will be valuable to public health agency managers and leaders. Organizational leaders and managers will be better equipped to understand the likely motivations of the workforce. In addition, individuals designing and executing training programs can market programs by appealing to the training motivations commonly reported among public health workers.

\section{Methods}

Items from PH WINS 2017 were used in a crosssectional, descriptive examination of reported motivations for seeking training both overall and across respondent demographics. PH WINS was administered in the fall of 2017 to a nationally representative sample of state health agency (SHA) and local health department (LHD) staff by the Association of State and Territorial Health Officials with support from the de Beaumont Foundation. The 4 major domains in the survey are (1) workplace environment, (2) training needs, (3) emerging concepts in public health, and (4) demographics. More details regarding the survey items, administration, sampling, and weighting strategy are covered in depth elsewhere in this supplement along with descriptive statistics of the entire PH WINS 2017 sample. $^{18}$

\section{Measures}

\section{Training motivations}

The PH WINS 2017 instrument included 1 item to assess motivations for seeking training, a key addition not present in the 2014 survey. Respondents selected all that applied from the following motivations: (1) maintenance of licensure; (2) training taken into account during performance reviews; (3) requirement for promotion; (4) peers taking the training; (5) expectations from a supervisor; (6) mandated by agency supervisor, management, or leadership; (7) covered time for training; (8) paid travel for training; (9) availability of applicable in-person trainings; (10) availability 
of applicable online trainings; (11) personal growth or interest; (12) other; and (13) none of the above.

\section{Demographic variables}

Respondents reported a number of demographic variables, a subset of which was used in the analyses. Gender was recorded as male, female, or nonbinary/other. Age was collapsed into 3 groups: 25 years or below, 26 to 45 years, and 45 years or above. Race and ethnicity were collected as American Indian or Alaska Native; Native Hawaiian or other Pacific Islander; black or African American; Asian; Hispanic or Latino; white; or 2 or more races. For analyses, these 7 categories were collapsed into 4: white, black or African American, Hispanic or Latino, and Other. Two variables related to education were included: public health degree holders (identified with a derived variable based on degree type and reported major ${ }^{19}$ ) and educational attainment (no college degree, associate, bachelor's, master's, or doctoral degree). Respondent role was grouped into 10 categories based on shared training areas. ${ }^{19}$ The role categories for the analyses were management, business support, nurses, other clinical workers, community health workers, environmental workers, epidemiologists, information technology staff, laboratory staff, and unspecified. Details on how roles were categorized are included in Supplemental Digital Content Appendix A (available at http://links.lww.com/JPHMP/A548). Finally, analyses included jurisdiction of the respondent-LHD or SHA.

\section{Training needs}

The training needs items constitute the largest portion of the PH WINS 2017 instrument and were revised substantially after the first PH WINS assessment. ${ }^{18}$ The domains for training needs included effective communication, data for decision making, cultural competency, budget and financial management, change management, cross-sectoral partnerships, systems and strategic thinking, and developing a vision for a healthy community. ${ }^{18}$ Although items were phrased differently based on respondents' supervisory status, training needs could be aggregated into these 8 training domains. Eight domain-specific training need variables were computed to indicate whether or not a respondent demonstrated a training need for any of the items within that domain (eg, change management). This dichotomization was undertaken to enable an easily interpretable relationship between demonstration of any training need within a domain rather than demonstration of a critical mass or plurality of training needs. That approach would misclassify some public health workers with narrow training needs as not having training needs. Finally, a ninth binary variable was constructed for "any training need" to indicate whether a respondent demonstrated any training need in any domain. Training needs are explored in more detail elsewhere in this supplement, ${ }^{20}$ and a list of all training needs items by supervisory status and domain can be found in Supplemental Digital Content Appendix B (available at http://links.lww. com/JPHMP/A548).

\section{Analyses}

To identify patterns of responses to the training motivation item, latent class analysis (LCA) was used. ${ }^{21}$ This technique identified groups of respondents based on indicated motivations for seeking training. The options of "other" and "none of the above" from the motivational class analysis variables were excluded. LCA is a common technique for identifying groups from sets of categorical variables. It seeks to identify patterns and "latent" variables that separate out groups that respond similarly. To find the optimal LCA model, 3 separate models were fit with 3, 4, and 5 latent classes, respectively. In determining the best fit model, the authors considered model fit statistics as well as the interpretability and discreteness of the classes. ${ }^{22}$ Then, respondents were assigned to the highest-probability "motivational class." ${ }^{\text {"23 }}$ Classes were described on the basis of the proportions of respondents who indicated each training motivation. The authors interpreted these motivational response patterns to identify different motivational classes.

Once classes were established, descriptive statistics for the sample were computed across the latent classes to describe the sample for analysis and to test for differences across the motivational classes. In addition, the most common training motivations overall were identified via survey-weighted frequency calculations. Next, the authors examined the proportions of each class demonstrating training needs in any of the 8 training domains and used $\chi^{2}$ analysis to test for differences across classes in training needs.

To examine the relationship between reported training needs and motivational factors for training, multivariate logistic regressions were conducted for each of the 8 training need domains among the 3 supervisory groups. An additional logistic regression was performed for respondents indicating a training need in any domain. In all 9 models, the covariates included motivational class, age, gender, race and ethnicity, holding a public health degree, educational attainment, role category, supervisory status, and jurisdiction (LHD or SHA). Odds ratios and 95\% confidence intervals were computed for all covariates. Finally, balanced repeated replication weights 
for complex sampling methodologies were utilized in all analyses. Both the sampling and weighting approaches for $\mathrm{PH}$ WINS are described in more detail elsewhere in this special issue. ${ }^{18}$ All analyses were conducted using $\mathrm{R}$ and $\mathrm{R}$ Studio statistical software, ${ }^{24,25}$ with a cutoff of $P<.05$ to measure significance. This study was approved by the Indiana University institutional review board and complies with all human participants requirements.

\section{Results}

\section{Training motivations}

Overall, the most common training motivator was personal growth; $82.7 \%$ of all respondents indicated this as a motivator for seeking out training. The second most common motivator was covered time for training $(53.8 \%)$, followed by availability of applicable in-person training opportunities $(52.6 \%)$. See Figure 1 for the overall percentages of respondents indicating each motivation.

\section{Latent class selection and class descriptions}

In LCA, the best model fit was attained with 4 latent classes. In addition to identifying visually discrete groups, the 4-class model improved upon the Bayesian Information Criterion from the 3-class model without overfitting the data. Model fit statistics for LCA models are available in Supplemental Digital
Content Appendix C (available at http://links.lww. com/JPHMP/A548). The response probabilities for each training motivation across the 4 latent classes can be seen in Figure 2, with response probabilities over $50 \%$ shaded gray. Class 1 (labeled "personal growth emphasis") comprised $21.7 \%$ of the sample, with individuals emphasizing personal growth as the primary-and often the only-training motivation. The second class was labeled "indiscriminately motivated" $(28.4 \%)$ because these individuals were more likely to indicate motivation by most or all of the available options. Class $3(18.2 \%)$ was labeled "organizational accommodation and delivery modality" because class members were more likely to emphasize covered time, paid travel, and delivery modality (online or in-person) as motivating factors. Finally, class $4(31.8 \%)$ was labeled "organizational pressure and requirements" as class members had higher likelihoods of indicating promotion, supervisor expectations, and mandates as motivating factors. This class was the largest of the 4 classes identified. The classes are referred in the remainder of the article as "personal growth," "indiscriminate," "organizational accommodation," and "organizational pressure."

\section{Respondent characteristics across classes}

The total number of respondents in our sample was 40383 , and respondents differed across classes in age category $(P<.001)$, race and ethnicity $(P=.001)$,

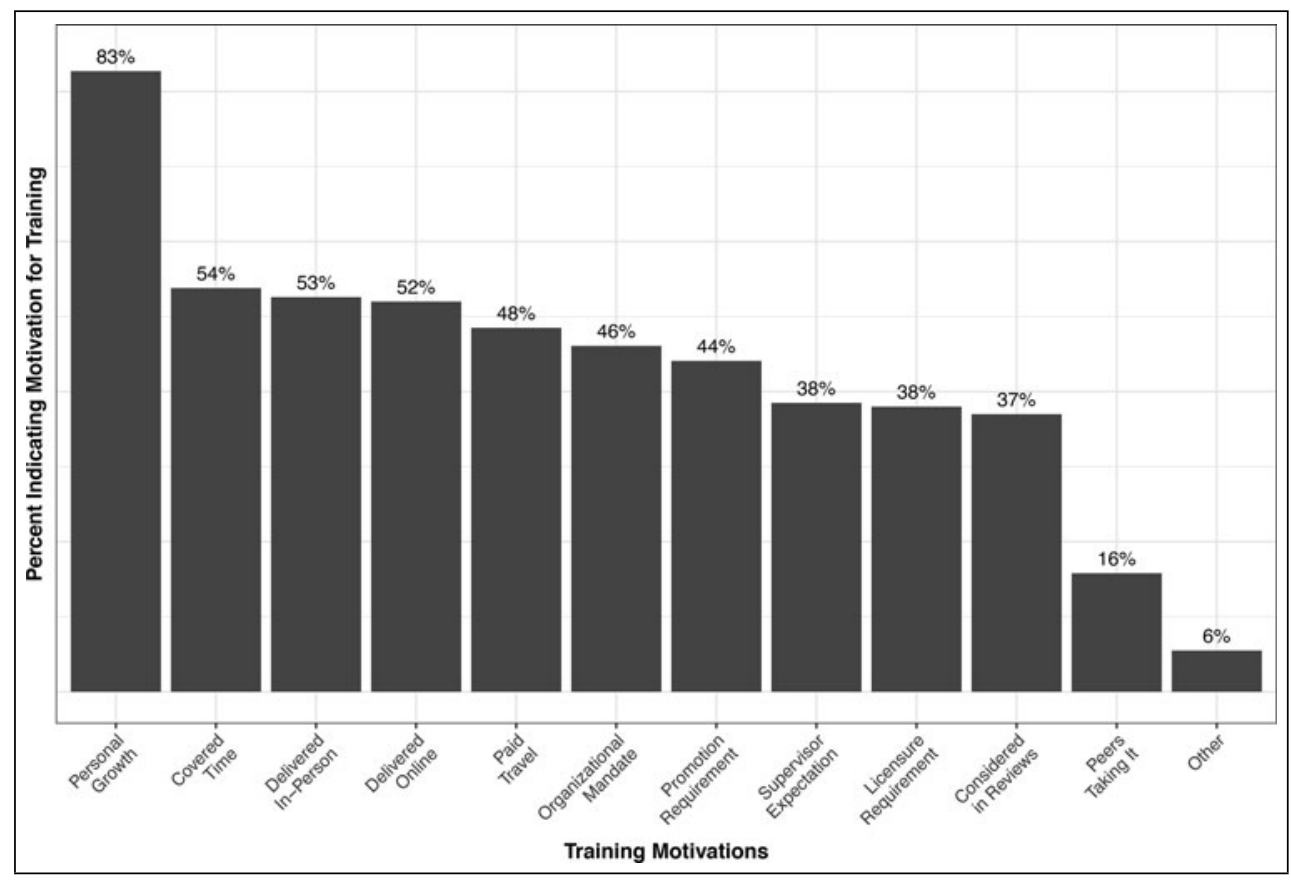

FIGURE 1 Overall Training Motivations 


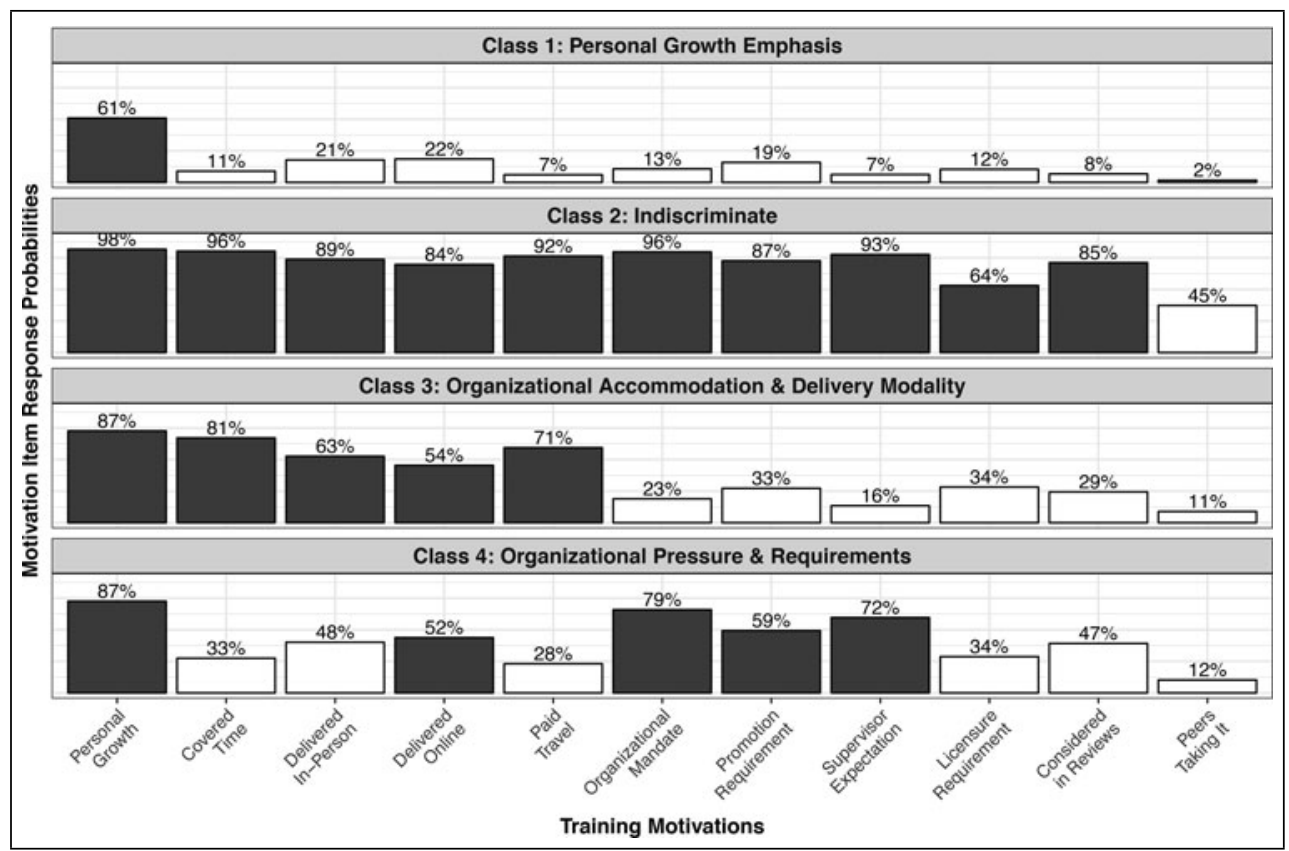

FIGURE 2 Training Motivation Responses by Class ${ }^{a}$

${ }^{a}$ Motivation items with more than $50 \%$ probability in gray.

education level $(P<.001)$, public health degree status $(P<.001)$, tenure in position $(P=.039)$, setting $(P<.001)$, governance structure $(P<.001)$, and role category $(P=.008)$. Across age categories, both the organizational accommodation class and organizational pressure class had higher proportions of respondents in the 26- to 45-year age group. The personal growth and organizational accommodation classes had higher proportions of white respondents, whereas the indiscriminate class had higher proportions of Hispanic or Latino respondents. Across levels of education, more respondents in both the organizational accommodation and organizational pressure classes had obtained master's degrees and more held public health degrees. Full descriptive statistics stratified by motivational class are presented in the Table.

\section{Training needs}

Training needs questions were analyzed by domain to allow for comparisons across supervisory status. In comparing training needs across motivational classes, no statistically significant differences were found in the proportion of the sample from each class reporting training needs in any domain. The percentages of respondents from each class reporting training needs in each domain are presented in Figure 3. In addition, in logistic regression analysis, class was not significantly associated with any domain-level training needs, nor was it associated with indicating any training need.
Full regression results for all models can be found in Supplemental Digital Content Appendix D (available at http://links.lww.com/JPHMP/A548).

\section{Discussion}

This study identified overarching training motivations across the sample of public health workers responding to PH WINS 2017. Personal growth was by far the most common training motivation among public health workers, with more than $80 \%$ of respondents indicating this as a motivational factor for seeking out training. No other motivation garnered more than $54 \%$ of respondents, illustrating a large gap between personal growth and other motivations. This finding suggests that appealing to the value of training opportunities for personal growth may be an effective motivator.

Using LCA, 4 salient patterns of motivational responses among public health workers were established. The first class, those primarily motivated by personal growth, appeared to be solely motivated by that factor regardless of other organizational supports provided or pressures from the organization. The second class, those who were indiscriminately motivated by most (or all) motivators, may not represent a pattern so much as it represents a lack of a pattern, which motivated the label for this group. Despite this "lack of pattern," the indiscriminate group did turn out to be the second largest class, which may be driven by the fact that responses indicating all motivational 


\section{TABLE}

Descriptive Statistics of Sample (Stratified by Class) ${ }^{\mathrm{a}}$

\begin{tabular}{|c|c|c|c|c|c|}
\hline & $\begin{array}{c}\text { Overall } \\
(\mathrm{N}=40383)\end{array}$ & $\begin{array}{c}\text { Class 1 }^{\mathrm{b}} \\
(\mathrm{n}=8761 ; 21.7 \%)\end{array}$ & $\begin{array}{c}\text { Class 2 } \\
\text { ( } n=11458 ; 28.4 \%)\end{array}$ & $\begin{array}{c}{\text { Class } 3^{\mathrm{d}}} \\
(\mathrm{n}=7335 ; 18.2 \%)\end{array}$ & $\begin{array}{c}\text { Class } 4^{\mathrm{e}} \\
(\mathrm{n}=12829 ; 31.8 \%)\end{array}$ \\
\hline \multicolumn{6}{|l|}{$\overline{\text { Age group, } \mathrm{n}(\%)^{\dagger}}$} \\
\hline$\leq 25 \mathrm{y}$ & $1111(2.8)$ & $215(2.5)$ & $201(1.8)$ & $291(4.1)$ & $404(3.3)$ \\
\hline $26-45 y$ & $16071(41.0)$ & $3273(38.3)$ & $3793(34.2)$ & $3518(49.0)$ & $5487(44.2)$ \\
\hline$\geq 46 \mathrm{y}$ & $22039(56.2)$ & $5051(59.2)$ & $7087(64.0)$ & $3372(47.0)$ & $6529(52.6)$ \\
\hline \multicolumn{6}{|l|}{ Gender, n (\%) } \\
\hline Male & $8780(21.9)$ & $2176(25.1)$ & $2629(23.2)$ & $1456(20.0)$ & $2519(19.8)$ \\
\hline Female & $30996(77.5)$ & $6472(74.5)$ & $8631(76.1)$ & 5779 (79.4) & $10114(79.6)$ \\
\hline Nonbinary/other & $244(0.6)$ & $38(0.4)$ & $81(0.7)$ & $47(0.6)$ & $78(0.6)$ \\
\hline \multicolumn{6}{|l|}{ Race/ethnicity, n (\%) ${ }^{g}$} \\
\hline Other & $4833(12.2)$ & $941(11.0)$ & $1433(12.8)$ & $812(11.2)$ & 1647 (13.2) \\
\hline Black/African American & $5868(14.8)$ & $1219(14.2)$ & $2003(17.9)$ & $743(10.3)$ & $1903(15.2)$ \\
\hline Hispanic or Latino & $5715(14.5)$ & $1064(12.4)$ & $2105(18.8)$ & $714(9.9)$ & $1832(14.6)$ \\
\hline White & $23113(58.5)$ & $5356(62.4)$ & $5659(50.5)$ & $4956(68.6)$ & $7142(57.0)$ \\
\hline \multicolumn{6}{|l|}{ Highest level of education, $n(\%)^{f}$} \\
\hline No college degree & $6904(17.3)$ & $1539(17.7)$ & $2773(24.6)$ & $796(10.9)$ & $1796(14.1)$ \\
\hline Associate's & $5737(14.4)$ & $1292(14.9)$ & $1843(16.3)$ & $870(11.9)$ & $1732(13.6)$ \\
\hline Bachelor's & $14643(36.6)$ & $3274(37.7)$ & $3670(32.5)$ & $2994(41.1)$ & $4705(37.0)$ \\
\hline Master's & $10452(26.2)$ & $2117(24.4)$ & $2408(21.4)$ & $2201(30.2)$ & $3726(29.3)$ \\
\hline Doctoral & $2229(5.6)$ & $468(5.4)$ & $581(5.2)$ & $431(5.9)$ & $749(5.9)$ \\
\hline Have public health degree, $n(\%)^{f}$ & $6209(15.4)$ & $1222(13.9)$ & $1241(10.8)$ & $1419(19.3)$ & $2327(18.1)$ \\
\hline \multicolumn{6}{|l|}{ Tenure in position, $\mathrm{n}(\%)^{\mathrm{h}}$} \\
\hline $0-5 y$ & $24807(63.0)$ & $5475(63.8)$ & $6204(55.7)$ & $5127(71.6)$ & $8001(63.9)$ \\
\hline $6-10 y$ & $6239(15.8)$ & $1373(16.0)$ & $1953(17.5)$ & $939(13.1)$ & 1974 (15.8) \\
\hline $11-15 y$ & $3782(9.6)$ & $792(9.2)$ & $1236(11.1)$ & $548(7.7)$ & $1206(9.6)$ \\
\hline $16-20 y$ & $2258(5.7)$ & $469(5.5)$ & $846(7.6)$ & $289(4.0)$ & $654(5.2)$ \\
\hline$\geq 21 \mathrm{y}$ & $2305(5.9)$ & $473(5.5)$ & $896(8.0)$ & $255(3.6)$ & $681(5.4)$ \\
\hline \multicolumn{6}{|l|}{ Tenure in public health practice, $n(\%)$} \\
\hline $0-5 y$ & $12468(32.2)$ & $2701(32.0)$ & $2989(27.5)$ & $2710(38.2)$ & 4068 (32.9) \\
\hline $6-10 y$ & $6973(18.0)$ & $1471(17.4)$ & $1905(17.5)$ & $1316(18.6)$ & $2281(18.4)$ \\
\hline $11-15 y$ & $5787(14.9)$ & $1254(14.9)$ & $1734(15.9)$ & $987(13.9)$ & $1812(14.6)$ \\
\hline $16-20 y$ & $4891(12.6)$ & $1056(12.5)$ & $1471(13.5)$ & $825(11.6)$ & 1539 (12.4) \\
\hline$\geq 21 \mathrm{y}$ & $8658(22.3)$ & $1949(23.1)$ & $2782(25.6)$ & $1252(17.7)$ & $2675(21.6)$ \\
\hline $\begin{array}{c}\text { Setting = Local health } \\
\text { department, } n(\%)^{\dagger}\end{array}$ & $24289(60.1)$ & 4970 (56.7) & $7281(63.5)$ & $4111(56.0)$ & 7927 (61.8) \\
\hline \multicolumn{6}{|l|}{ Governance structure, $n(\%)^{\dagger}$} \\
\hline Centralized/largely centralized & 8001 (19.8) & $1703(19.4)$ & $2322(20.3)$ & $1381(18.8)$ & $2595(20.2)$ \\
\hline Shared/largely shared & $8529(21.1)$ & $1964(22.4)$ & $2769(24.2)$ & $1292(17.6)$ & 2504 (19.5) \\
\hline $\begin{array}{l}\text { Decentralized/largely } \\
\text { decentralized }\end{array}$ & $20550(50.9)$ & 4371 (49.9) & $5501(48.0)$ & $3968(54.1)$ & $6710(52.3)$ \\
\hline Mixed & 3303 (8.2) & $723(8.3)$ & $866(7.6)$ & $694(9.5)$ & $1020(8.0)$ \\
\hline \multicolumn{6}{|l|}{ Role category, $\mathrm{n}(\%)^{\mathrm{g}}$} \\
\hline Business support & $10664(27.3)$ & $2660(31.2)$ & $3431(31.3)$ & $1783(24.9)$ & $2790(22.4)$ \\
\hline Community health worker & $4178(10.7)$ & $742(8.7)$ & $1219(11.1)$ & $719(10.0)$ & $1498(12.0)$ \\
\hline Environmental worker & $2690(6.9)$ & $600(7.0)$ & $639(5.8)$ & $600(8.4)$ & $851(6.8)$ \\
\hline Epidemiologist & $1462(3.7)$ & $267(3.1)$ & $274(2.5)$ & $346(4.8)$ & $575(4.6)$ \\
\hline IT & $1342(3.4)$ & $352(4.1)$ & $377(3.4)$ & $219(3.1)$ & $\begin{array}{l}394(3.2) \\
\quad \text { (continues) }\end{array}$ \\
\hline
\end{tabular}




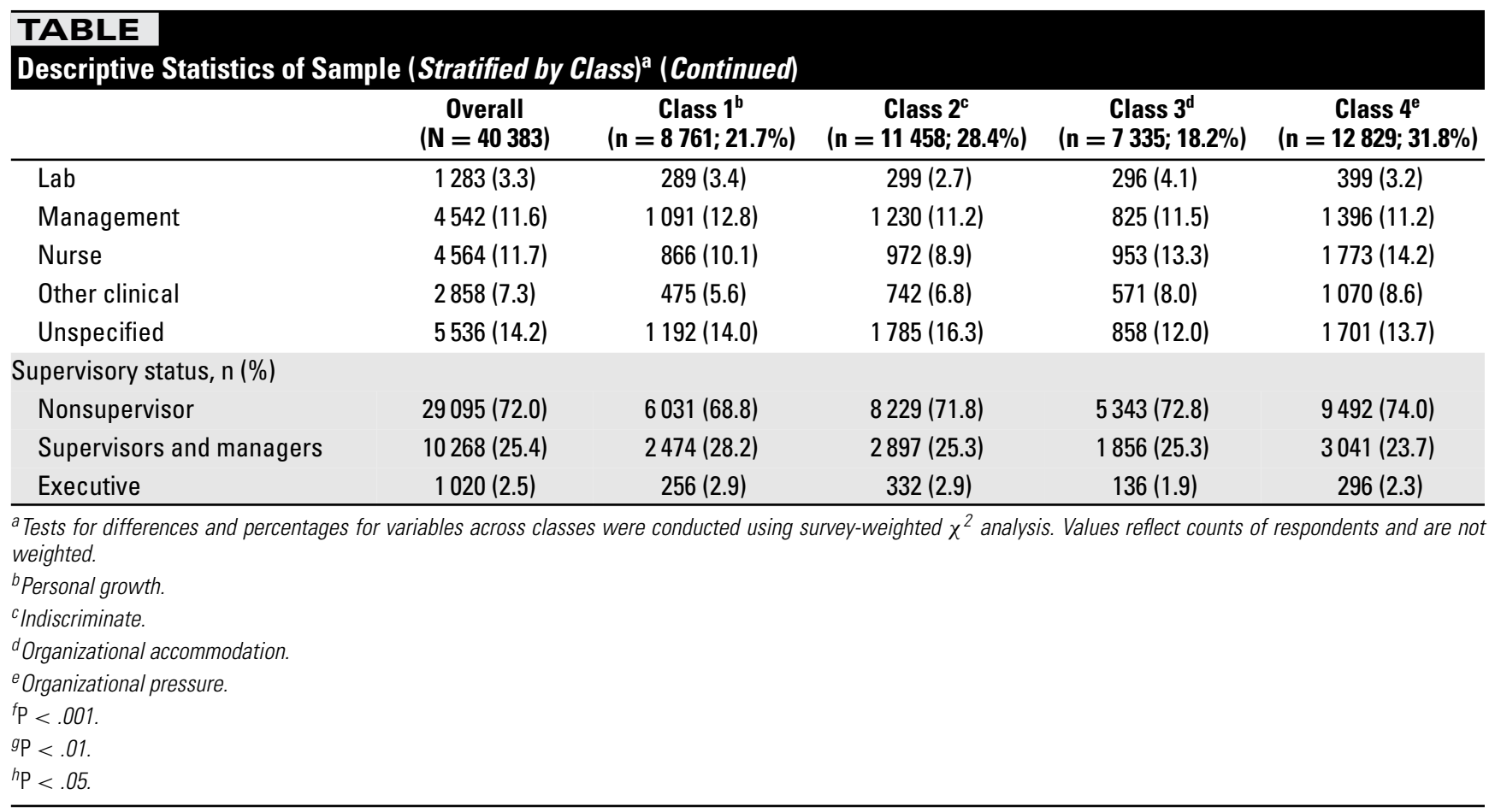

factors as important were the modal response to this item.

Unlike these 2 classes with somewhat onedimensional patterns of motivation, the 2 remaining motivational classes were more instructive. Primarily, these 2 classes identified 2 groups of respondents who sought different organizational treatment of training programs. These 2 classes also comprised about half of the total population. Respondents in the organizational pressure class-about 1 in 3 workers-were

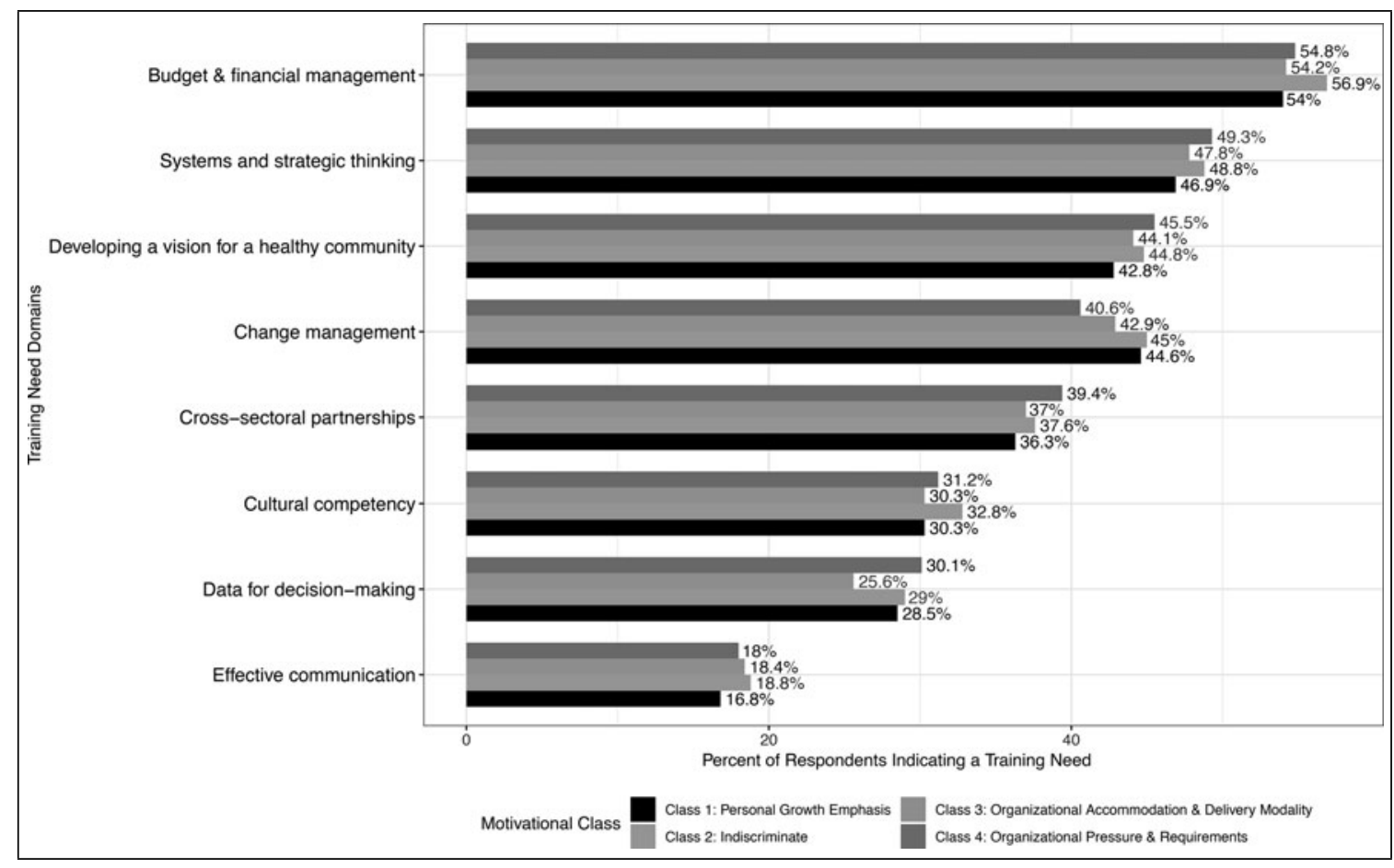

FIGURE 3 Training Needs by Domain: Across Motivational Classes 
more likely to be motivated by promotion, mandates, or incorporation of training into performance reviews. Alternatively, organizational accommodation respondents-about 1 in 5 public health workerswere primarily motivated by organizational supports such as paid time for training and funding for travel to training events. These motivational factors fall neatly into 2 sets of organizational approaches to incentivize training, namely, (1) administrative steps to formally ingrain training in the promotional process and (2) more robust financial support to fund workers via paid time or travel. The division of the workforce across these 2 classes suggests that public health agencies may want to take a "both/and" approach rather than choosing between formal requirements or support in the form of funding.

The study found no associations between motivational class and perceived training needs. All training need domains were just as prominent across motivational classes, indicating that the motivational patterns described earlier cut across training need domains. Even in regression analyses, motivational class was not associated with any training needs. This implies that motivational factors are not specific to training need domains; rather, they are more likely related to individual characteristics.

Ultimately, these findings reveal no one solution guaranteed to motivate public health workers to seek out training. Indeed, the motivational classesespecially those featuring organizational responses to motivate workers-illustrate differentially motivated segments of the public health workforce. Future research should investigate 2 aspects of these findings. First, a more detailed look at individual training needs, rather than domain-level analysis, may show that motivational class differs for more narrowly defined training needs. Second, a more robust examination of worker characteristics associated with patterns of motivations may be valuable in targeting certain groups that demonstrate greater training needs.

Our study has several limitations, most prominently the difficulty determining the appropriate number of classes for LCA. ${ }^{22}$ Given the complexity of model comparison, multiple LCA models were examined, similar to previous work using this method. ${ }^{23}$ In addition, the authors incorporated a visual method to identify discrete classes, given the response probabilities for each motivational factor to ensure the revealed patterns could be meaningfully differentiated. Also, in aggregating training need questions into the 8 training domains, the analysis necessarily removed some variation in the training needs data. Given the challenge of stratifying both by class and supervisory status, this aggregation was necessary for the purpose of the study's analyses and to clearly present findings.

\section{Implications for Policy \& Practice}

- Personal growth motivates seeking training for the vast majority $(82.7 \%)$ of the public health workforce. Agencies and program designers should emphasize personal growth in informational materials for training programs.

- Four motivational classes were revealed via LCA. First, those motivated by organizational pressures such as mandates and requirements for promotion were the largest group and made up $31.8 \%$ of respondents. Second, those indiscriminately motivated by all factors comprised $28.4 \%$ of respondents. Third, those motivated primarily by personal growth made up $21.7 \%$ of respondents. Fourth, $18.2 \%$ of respondents were motivated by factors related to organizational accommodations for seeking training, such as paid time for training and paid travel. While implementing organizational requirements is easier to execute, these solutions may fail to motivate a large swath of the workforce primarily motivated by organizational accommodations.

- The largest and smallest motivational classes represent discrete strategies organizations can take to incentivize training. These findings suggest that organizations need not choose between these 2 options, as these classes represent almost half of the workforce.

- Motivational class was not associated with exhibiting any training need overall or in any training domain, indicating that motivational strategies can be used to various training ends, as motivations cut across training domains.

Furthermore, the identification of training needs depends on the perception of the respondent, insofar as they must perceive a skill as important to their role. If respondents incorrectly indicate a skill as important to their role, they may show a training need for that skill when in fact the skill is irrelevant. This could, in turn, bias the results, as these perceived training needs were analyzed across motivational classes and as dependent variables in regression. There also exists a risk of response bias, as is true for any survey-based analysis. Use of BRR weights attempts to correct for this bias; however, some response bias may remain. Finally, the study design is inherently descriptive rather than causal, given the cross-sectional nature of the data.

Four discrete patterns of training motivations were identified among the public health workforce respondents to the PH WINS 2017 instrument: personal growth focus, indiscriminate motivation, organizational pressure and requirements as motivators (the largest group), and organizational accommodation and support as motivators. We found no differences in training needs across these motivational groups, 
indicating that motivations likely cut across perceived training needs. These findings suggest that agencies implementing training programs or organizations funding public health training programs may find higher worker training motivation when using crosscutting motivational approaches. These approaches should emphasize personal growth and need not choose between organizational pressures such as promotional requirements or accommodation such as paid travel for training events, as the workforce is split across these motivational classes.

\section{References}

1. Bunker JP, Frazier HS, Mosteller F. Improving health: measuring effects of medical care. Milbank Q. 1994;72(2):225-258. https://www. ncbi.nlm.nih.gov/pubmed/8007898. Accessed June 7, 2018.

2. Ten great public health achievements-United States, 1900-1999. https://www.cdc.gov/mmwr/preview/mmwrhtml/mm6019a5.htm. Published April 2, 1999. Accessed June 7, 2018.

3. US Burden of Disease Collaborators; Mokdad AH, Ballestros K et al. The state of US health, 1990-2016: burden of diseases, injuries, and risk factors among US states. JAMA. 2018;319(14):14441472.

4. Mokdad AH, Serdula MK, Dietz WH, Bowman BA, Marks JS, Koplan JP. The spread of the obesity epidemic in the United States, 1991-1998. JAMA. 1999;282(16):1519-1522. https://www.ncbi.nlm. nih.gov/pubmed/10546690. Accessed June 7, 2018.

5. Rudd RA, Seth P, David F, Scholl L. Increases in drug and opioidinvolved overdose deaths-United States, 2010-2015. MMWR Morb Mortal Wkly Rep. 2016;65(5051):1445-1452.

6. Dietz WH. The response of the US Centers for Disease Control and Prevention to the obesity epidemic. Annu Rev Public Health. 2015;36:575-596. http://www.annualreviews.org/doi/abs/10.1146/ annurev-publhealth-031914-122415. Accessed June 7, 2018.

7. Houry DE, Haegerich TM, Vivolo-Kantor A. Opportunities for prevention and intervention of opioid overdose in the emergency department. Ann Emerg Med. 2018;71(6):688-690.

8. Bigley MB. HRSA's transformation of public health training. Public Health Rep. 2016;131(1):4-6.

9. Sellers K, Leider JP, Harper E, et al. The Public Health Workforce Interests and Needs Survey: the first national survey of state health agency employees. J Public Health Manag Pract. 2015;21(suppl 6):S13-S27.

10. Dixon BE, McFarlane TD, Dearth S, Grannis SJ, Gibson PJ. Characterizing informatics roles and needs of public health workers: results from the Public Health Workforce Interests and Needs Survey. J Public Health Manag Pract. 2015;21(suppl 6):S130-S140.

11. Yeager VA, Wisniewski JM, Chapple-McGruder T, Castrucci B, Gould E. Public health workforce self-identified training needs by jurisdiction and job type. J Public Health Manag Pract. June 2018 doi:10.1097/PHH.0000000000000830

12. Grimm BL, Johansson P, Nayar P, Apenteng BA, Opoku S, Nguyen A. Assessing the education and training needs of Nebraska's public health workforce. Front Public Health. 2015;3:161.

13. Jacob RR, Baker EA, Allen $P$, et al. Training needs and supports for evidence-based decision making among the public health workforce in the United States. BMC Health Serv Res. 2014;14: 564.

14. Chapple-McGruder T, Leider JP, Beck AJ, et al. Examining state health agency epidemiologists and their training needs. Ann Epidemiol. 2017;27(2):83-88.

15. Massoudi BL, Chester K, Shah GH. Public health staff development needs in informatics: findings from a national survey of local health departments. J Public Health Manag Pract. 2016;22(suppl 6), Public Health Informatics:S58-S62.

16. Ye J, Leep C, Robin N, Newman S. Perception of workforce skills needed among public health professionals in local health departments: staff versus top executives. J Public Health Manag Pract 2015;21(suppl 6):S151-S158

17. Wilcox LS, Majestic EA, Ayele M, Strasser S, Weaver SR. National survey of training needs reported by public health professionals in chronic disease programs in state, territorial, and local governments. J Public Health Manag Pract. 2014;20(5):481-489.

18. Leider JP, Pineau V, Bogaert K, Ma Q. The methods of PH WINS 2017: Approaches to refreshing nationally-representative statelevel estimates and creating nationally-representative local-level estimates of public health workforce interests and needs. J Public Health Manag Pract. 2019;25(suppl 2):S49-S57.

19. Leider JP, Harper E, Bharthapudi K, Castrucci BC. Educational attainment of the public health workforce and its implications for workforce development. J Public Health Manag Pract 2015;21 (suppl 6):S56-S68.

20. Bogaert K, Castrucci B, Gould E, Rider N, Whang C, Corcoran. Top training needs of governmental public health departments. J Public Health Manag Pract. 2019;25(suppl 2):S134-S144.

21. Hagenaars JA, McCutcheon AL. Applied Latent Class Analysis. Cambridge, England: Cambridge University Press; 2002. https:// www.researchgate.net/profile/Allan_Mccutcheon/publication/ 238190464_Applied_Latent_Class_Analysis_Models/links/0a85e 5397083ddf43e000000.pdf. Accessed November 22, 2018.

22. Nylund KL, Asparouhov T, Muthén BO. Deciding on the number of classes in latent class analysis and growth mixture modeling: a Monte Carlo simulation study. Struct Equ Model. 2007:14(4):535569.

23. Hu H, Allen $P$, Yan $Y$, Reis RS, Jacob RR, Brownson RC. Organizational supports for research evidence use in state public health agencies: a latent class analysis. J Public Health Manag Pract. May 2018. doi:10.1097/PHH.0000000000000821.

24. R Core Team. R: A Language and Environment for Statistical Computing. Vienna, Austria: R Foundation for Statistical Computing; 2018. https://www. R-project.org. Accessed October 21, 2017.

25. RStudio Team. R Studio. Boston, MA: R Studio; 2015. http://www. rstudio.com. Accessed October 21, 2017. 